\title{
Investigation of Education Requirements of Individuals Using Warfarin and Achievement of Target INR Value
}

\author{
Fadime Çınar $^{1(D), ~ H a y a t ~ Y a l ı n ~}{ }^{2}$ (D), Fatma Eti Aslan 2,*(D) \\ 1 Nisantasi University, College of Health Sciences, Department of Nursing, Istanbul, Turkiye \\ 2 Bahçeşehir University Faculty of Health Sciences, Nursing Istanbul, Turkiye \\ * Correspondence: fadime.cinar@nisantasi.edu.tr (F.Ç.);
}

Scopus Author ID 57204505449

Received: 13.07.2021; Revised: 5.10.2021; Accepted: 8.10.2021; Published: 19.12.2021

\begin{abstract}
Thromboembolic diseases are important causes of morbidity and mortality. Oral anticoagulants for preventing or treating thromboembolic diseases reduce blood clotting and prevent fibrin deposition, thrombus development, and growth. This study aimed to investigate the educational needs and the rate of reaching the target INR level of individuals using warfarin for heart diseases. The population of this cross-sectional study was attempted to reach the entire population by not choosing a sample due to heart diseases between August -September 2019 in the cardiology outpatient clinic of a public hospital operating in Istanbul. However, due to the voluntary basis and incorrect registration of the questionnaires, 157 participants formed the sample. Data were analyzed using the SPSS 25.0 program. $75.1 \%$ of the individuals stated that they were informed about the use of warfarin, and $66.8 \%$ of those who received the information stated that they received the information from their physician. In addition, $75.7 \%$ stated that they took warfarin regularly, $81.7 \%$ had regular INR control, $52.1 \%$ knew the target INR value, $68.9 \% \mathrm{knew}$ the complications. It was found to be 47.6. A statistically significant difference was found between individuals who reached the target INR level and those who did not, according to their information acquisition status $(\mathrm{p}<0.05)$. The low rate of individuals reaching the target INR level draws attention. For this reason, it is thought that the knowledge level of patients who are starting treatment with warfarin should be increased, and new generation oral anticoagulant drugs can be used as an anticoagulant treatment instead of warfarin in patients whose target INR cannot be achieved despite sufficient training.
\end{abstract}

Keywords: warfarin; anticoagulants; patient education as a topic.

(C) 2021 by the authors. This article is an open-access article distributed under the terms and conditions of the Creative Commons Attribution (CC BY) license (https://creativecommons.org/licenses/by/4.0/).

\section{Introduction}

Thromboembolic diseases cause significant morbidity and mortality. Oral anticoagulants for preventing or treating thromboembolic diseases reduce fibrin accumulation, thrombus development, and growth by reducing blood clotting. The drugs in this group disrupt the synthesis of factors II, VII, IX, X synthesized in the liver [1-3]. Warfarin is the most used drug because it has the best bioavailability and least serious side effects among oral anticoagulants [3]. Warfarin is widely used for the prevention and treatment of deep vein thrombosis (DVT), pulmonary embolism, prophylaxis of thromboembolic events after acute coronary events, rheumatic heart valve diseases, mechanical heart valve prosthesis surgery, atrial fibrillation (AF), and ischemic cerebrovascular diseases [3-6]. Long-term use of warfarin is essential for life [7]. Especially in patients with AF, long-term [8] and life-long anti-clotting is mandatory to prevent thromboembolic complications in patients with mechanical heart 
valves [9] Despite its vital importance and its widespread use, the narrow therapeutic range of warfarin and the effect of individual differences due to food, medicine, genetic factor, and age require follow-up of patients under treatment. International normalization rate (INR) is used for warfarin's safe and effective use [10-12]. Target INR value; It is recommended to keep between 2.5-3.5 in patients with the mechanical prosthetic mitral valve, 2.0-3.0 in patients with the mechanical prosthetic aortic valve, 2.0-3.0 in patients with atrial fibrillation (AF), pulmonary embolism, and deep vein thrombosis [10]. Patients using warfarin often encounter bleeding and embolism because the INR level is outside the target range during treatment.

Lack of knowledge about anticoagulant therapy [3,13] and insufficient knowledge on drug-drug interactions and drug-food interactions [3]. The need to go to the hospital for blood tests, diet and activity restrictions, and the possibility of bleeding [14] can negatively affect achieving the target INR value. A study found that the knowledge level of education was emphasized in the use of warfarin and that the level of the pre-education level was significantly increased after the education. This result emphasizes that with increasing education, Warfarinrelated complications will decrease, and accordingly, the cost will decrease [15]. As healthcare professional who spends the most time with the patient, nurses should use their knowledge and skills to advise and inform their patients at every stage of treatment. To achieve this, evaluating patients' knowledge and perceptions of treatment is a priority. This assessment should include many factors related to the disease and treatment process, and the expectations and needs of patients should be determined by the nurse. The nurses should handle the identified problems systematically, and the solution steps should be reviewed with the patient. The long-term treatment of the patients using warfarin, its effectiveness, dependence on many factors, and the seriousness of complications that may develop are issues that should be especially emphasized in nursing services. To guide the application of nurse counseling both individually and as a group, it was aimed to evaluate the knowledge and perceptions of treatment and educational needs of patients using warfarin to evaluate the relationship between this requirement and the rate of reaching the target INR level. It is thought that determining the training needs will contribute to the effective implementation of the treatment and prevention of complications by conducting patient education. For the research, answers were sought for two research questions: What information should individuals using warfarin know while using the drug (knowing the reason for using warfarin, knowing the dose of warfarin, following the INR value, knowing the INR value range...)? What is the effect of warfarin users' individual and drug use knowledge on the target INR value?

\section{Materials and Methods}

\subsection{Design.}

This descriptive and cross-sectional study aimed to investigate the relationship between the educational needs of individuals using warfarin due to heart disease and the rate of reaching the target INR level.

\subsection{Participants and settings.}

The research used warfarin in the cardiology outpatient clinic of a public hospital operating in Istanbul, between August and September 2019, because of heart diseases and 213 patients who underwent INR follow-up. The entire universe was asked to be reached by not 
choosing the sample. However, 157 participants formed the sample due to voluntary and incorrect questionnaires recording.

\subsection{Data collection tools.}

The data were collected by face-to-face interviews with individual questionnaires prepared by researchers $[10,13,16]$. The questionnaire includes 11 questions regarding age, gender, educational status, presence of chronic disease, 5 questions evaluating the drugs used continuously, Warfarin use cases, and INR values. After the pilot study with 30 people to determine the comprehensibility of the survey questions, the number of questions in the survey and some questions that were difficult to understand were changed; A new questionnaire was created in line with the answers given by the individuals participating in the pilot study.

The data was collected during a face-to-face interview through a questionnaire form containing questions about target INR rates using warfarin with participants who agreed to participate in the research followed by INR in the cardiology outpatient clinic of the cardiology outpatient clinic public hospital where the research was conducted. Data collection took approximately 10-15 minutes for each participant. The dose of the drug was determined by the International Normalized Ratio [10,17] by the polyclinic physicians, and the participants were monitored according to the indications of warfarin use and the target INR level. This information was recorded in the patient follow-up file. The drug dose was adjusted by calculating the rate of reaching the target INR level of the patients followed in these records. The preliminary application of the study was carried out with 15 individuals who applied to the cardiology outpatient clinic on January 4, 2019. As a result of the pre-application, the data of the individuals participating in the pre-application were included in the study without changing the data collection form.

\subsection{Ethical aspect of the research.}

In this study, a work permit was obtained from a foundation university Ethics Committee and hospital management (Ethics approval no: 2019/07). The purpose of the study was explained to the patients who participated in the study. After it was stated that the participation was voluntary, the written and verbal consent of those willing to participate in the study was obtained.

\subsection{Limitations of the study.}

The main limitations of this study were that the sample did not represent all patients using warfarin but only followed up in the outpatient clinic of a public hospital operating in the province of Istanbul. Additionally, the design type of the study was cross-sectional. This study was conducted following the Declaration of Helsinki Principles.

\subsection{Data analysis.}

The data were analyzed using SPSS 25.0 program. Categorical variables were calculated as numbers or percentages, and continuous variables were calculated as mean \pm standard deviation. The Chi-square test was used to compare categorical variables. In comparing the continuous variables, the compatibility of the parameters with the normal distribution was first evaluated with the Kolmogorov-Smirnov test. Wan Whitney U test was 
used to compare the data that did not fit the normal distribution. A P-value below 0.05 was considered statistically significant.

\section{Results and Discussion}

When the distribution of the descriptive characteristics of the individuals included in the study was examined (Table 1), the average age of the participants was $61 \pm 13,59.87 \%$ were women, $42.67 \%$ were in the age range of 60 and over, and $29.93 \%$ were in primary education. It was determined to be a graduate. Oral anticoagulant drugs have vital risks due to their side effects. For this reason, the patient and his or her family should be informed during the treatment, and the patient should be followed up with. The literature states that women who use oral anticoagulants and older people need to be treated more carefully in terms of adjusting the dosage and frequency of complications. Elderly individuals have more problems with forgetting and understanding, depending on their age, affecting adherence to treatment [3]. One study states that patients aged 80 and over are at risk compared to all patients receiving an inadequate education. Oral clot prevention prevents drug complications [18]. In women, an overdose of anticoagulants can cause heavy menstrual bleeding. Therefore, it is much more important to identify the educational deficiencies of these groups regarding the use of warfarin [3].

The study determined that $61.78 \%$ of individuals had another chronic disease, and $63.69 \%$ had medication that they used continuously (Table 1). It is stated in the literature that additional diseases and drug interactions effect (increase/decrease the effect) warfarin dose [13, 19, 20]. Qurkie et al. (2007), in their work, stated that drug interactions are a major factor (43\%) in the development of hemorrhage, which is the most serious complication of warfarin [21]. It has been determined that 73.7 of them are constantly using other drugs in addition to warfarin $[13,22]$. According to these results, it is thought that informing individuals and their families about the existing diseases and warfarin-drug interaction and raising awareness about the combined use of drugs will contribute to the safe maintenance of Warfarin treatment.

Table 1. Distribution of Descriptive Characteristics of Individuals Using Warfarin $(\mathrm{N}=157)$.

\begin{tabular}{|c|c|c|c|}
\hline \multicolumn{2}{|c|}{ Features } & \multirow[t]{2}{*}{ Number } & \multirow[t]{2}{*}{$\%$} \\
\hline \multirow{4}{*}{ Age } & Mean age: $61 \pm 13$ & & \\
\hline & $<50$ year & 37 & 23.56 \\
\hline & $50-59$ & 53 & 33,75 \\
\hline & 60 and above & 67 & 42.67 \\
\hline \multirow{2}{*}{ Gender } & Female & 63 & 40.12 \\
\hline & Male & 94 & 59.87 \\
\hline \multirow{5}{*}{ Education } & Not literate & 22 & 14.01 \\
\hline & Primary education & 47 & 29.93 \\
\hline & Middle school & 42 & 26.75 \\
\hline & High school & 27 & 17.19 \\
\hline & High education & 19 & 12.10 \\
\hline \multirow{2}{*}{ The presence of another chronic disease } & Yes & 97 & 61.78 \\
\hline & No & 60 & 38.21 \\
\hline \multirow{2}{*}{ Continuously usede medicines } & Yes & 100 & 63.69 \\
\hline & No & 57 & 36.30 \\
\hline \multirow{5}{*}{ Medical diagnosis } & Atrial fibrillation & 54 & 34.39 \\
\hline & Heart valve disease & 46 & 29.29 \\
\hline & Deep vein thrombosis & 14 & 8,91 \\
\hline & Pulmonary embolism & 27 & 17.19 \\
\hline & Mechanical prosthetic heart valve & 16 & 10.19 \\
\hline \multicolumn{2}{|c|}{ Total } & 157 & 100 \\
\hline
\end{tabular}


When the distribution of information that participants should know while using warfarin was examined, $70.71 \%$ knew the reason for using warfarin, $87.89 \%$ did not carry an identity or document regarding the use of warfarin $61.8 \%$ of the patients were 5 years or less. It was determined that $32.84 \%$ used this drug for some time, and they knew the dose of warfarin. When asked to be informed about warfarin, $74.52 \%$ were informed,66.8\% received this information from their physician, $75.79 \%$ used warfarin regularly, $81.52 \%$ had regular INR control, and $52.22 \%$ determined the target INR value, and $43.94 \%$ knew the complications. When the level of knowledge about warfarin-food interaction is questioned, $69.42 \%$ of them do not know, $64.33 \%$ of them do not know about the situations and emergencies that should be considered during their daily life activities, and $40.76 \%$ of them should report to physicians and nurses (Table 1). It was determined that he did not know the necessary conditions. In their study conducted by Köksal and Avşar (2015), it was determined that more than half of the patients did not know the dose of oral anticoagulants (OAC) [3]. In the study conducted by Mercan and Enç (2011), it was found that $81.6 \%$ of the patients did not know the dose of warfarin, an oral anticoagulant [13].

According to the diagnoses of the individuals included in the study, it was determined that the rate of reaching the target INR value was $47.7 \%$, and the patients who were diagnosed with atrial fibrillation with a maximum of $38.6 \%$ reached the target INR rate (Table 2).

Table 2. The Status of Reaching the Target INR Rate According to the Causes of Warfarin Treatment.

\begin{tabular}{l|c} 
Indication (n) & Reaching the target INR $\mathbf{n}(\boldsymbol{\%})$ \\
\hline Atrial fibrillation (54) & $29(38.6)$ \\
\hline Heart valve disease (46) & $23(30.6)$ \\
\hline Deep vein thrombosis (14) & $3(4)$ \\
\hline Pulmonary embolism (27) & $14(18.6)$ \\
\hline Mechanical prosthetic heart valve (16) & $6(8)$ \\
\hline Total (157) & $75(47.7)$
\end{tabular}

According to the level of education, knowing the reason for warfarin use, knowing the warfarin dose that should be used, informing about warfarin, and knowing the complications in the analyzes performed to determine whether there is a significant difference between the patient group who reached the target INR level and the group that did not reach, and the information status regarding the use of warfarin, there was a difference. According to the level of education, it was determined that the difference was due to primary school graduates who could not reach the target INR level, the difference was due to those who knew the cause of warfarin use and that the rate of those who knew the reason was higher than the target INR value. It was determined that those who knew the warfarin dose, those who received information about warfarin, and those who knew the complications had a high rate of achieving the target INR, which was the reason for the significant difference.

Table 3. Comparison of the parameters examined according to reaching the target INR level.

\begin{tabular}{|c|c|c|c|c|c|}
\hline Variable & $\begin{array}{l}\text { Mean } \pm \text { SD } / \\
\text { n }(\%)\end{array}$ & $\begin{array}{l}\text { Reaching the Target } \\
\text { INR Value }(n=75) \\
\text { Mean } \pm \text { SD / } \\
\text { n }(\%)\end{array}$ & 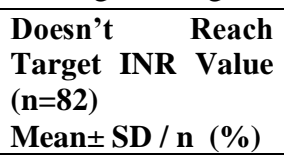 & $\mathbf{P}$ & $\mathbf{X}^{2} / \mathbf{U}$ \\
\hline $\begin{array}{l}\text { Mean age } \\
<50 \text { years old } \\
50-59 \\
60 \text { and over } \\
\end{array}$ & $\begin{array}{l}61 \pm 13 \\
37 \\
53 \\
67 \\
\end{array}$ & $\begin{array}{l}62.2 \pm 6.1 \\
21(42) \\
27(24) \\
27(24) \\
\end{array}$ & $\begin{array}{l}61.7 \pm 5.6 \\
16(46) \\
26(14) \\
40(36) \\
\end{array}$ & $0.895^{*}$ & 0.122 \\
\hline $\begin{array}{l}\text { Gender } \\
\text { Female }(\%) \\
\text { Male }(\%)\end{array}$ & $\begin{array}{l}63 \\
94 \\
\end{array}$ & $\begin{array}{l}27(54) \\
48(46)\end{array}$ & $\begin{array}{l}36(24) \\
46(76)\end{array}$ & 0.574 & 0.250 \\
\hline Education & & & & 0.015 & 4.028 \\
\hline
\end{tabular}




\begin{tabular}{|c|c|c|c|c|c|}
\hline Variable & $\begin{array}{l}\text { Mean } \pm \text { SD } / \\
\text { n }(\%)\end{array}$ & $\begin{array}{l}\text { Reaching the Target } \\
\text { INR Value }(n=75) \\
\text { Mean } \pm \text { SD / } \\
\text { n }(\%)\end{array}$ & 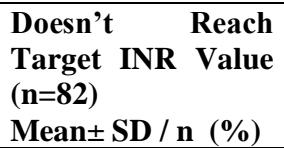 & $\mathbf{P}$ & $\mathbf{X}^{2} / \mathbf{U}$ \\
\hline $\begin{array}{l}\text { Not literate } \\
\text { Primary education } \\
\text { Midlle school } \\
\text { High school } \\
\text { High education }\end{array}$ & $\begin{array}{l}22 \\
47 \\
42 \\
27 \\
19\end{array}$ & $\begin{array}{l}8(36) \\
12(32) \\
19(8) \\
22(10) \\
14(14) \\
\end{array}$ & $\begin{array}{l}14(36) \\
35(36) \\
23(8) \\
5(12) \\
5(16) \\
\end{array}$ & & \\
\hline $\begin{array}{l}\text { Knowing warfarin using cause } \\
\text { Knows } \\
\text { Doesn't know }\end{array}$ & $\begin{array}{l}111 \\
46\end{array}$ & $\begin{array}{l}70 \\
5\end{array}$ & $\begin{array}{l}41 \\
41 \\
\end{array}$ & 0.028 & 3.167 \\
\hline $\begin{array}{l}\text { Warfarin using time } \\
5 \text { years and under } \\
6-10 \text { years } \\
11 \text { years and over }\end{array}$ & $\begin{array}{l}97 \\
24 \\
36 \\
\end{array}$ & $\begin{array}{l}35(20) \\
17(80) \\
23\end{array}$ & $\begin{array}{l}86(22) \\
7(78) \\
13 \\
\end{array}$ & 0.848 & 1.012 \\
\hline $\begin{array}{l}\text { Knowing the warfarin dose } \\
\text { Knows } \\
\text { Doesn't know }\end{array}$ & $\begin{array}{l}50 \\
107 \\
\end{array}$ & $\begin{array}{l}47(74) \\
28(26) \\
\end{array}$ & $\begin{array}{l}3(78) \\
79(22)\end{array}$ & 0.012 & 4.132 \\
\hline $\begin{array}{l}\text { Information about warfarin } \\
\text { Yes } \\
\text { No }\end{array}$ & $\begin{array}{l}117 \\
40\end{array}$ & $\begin{array}{l}67 \\
8 \\
\end{array}$ & $\begin{array}{l}50 \\
32 \\
\end{array}$ & 0.032 & 4.574 \\
\hline $\begin{array}{l}\text { Regular use of warfarin } \\
\text { Yes } \\
\text { No } \\
\end{array}$ & $\begin{array}{l}119 \\
38 \\
\end{array}$ & $\begin{array}{l}62 \\
13 \\
\end{array}$ & $\begin{array}{l}57 \\
25 \\
\end{array}$ & 0.006 & -3.097 \\
\hline $\begin{array}{l}\text { Regular INR checking } \\
\text { Yes } \\
\text { No }\end{array}$ & $\begin{array}{l}128 \\
29 \\
\end{array}$ & $\begin{array}{l}64 \\
11 \\
\end{array}$ & $\begin{array}{l}64 \\
18\end{array}$ & 0.285 & 0.432 \\
\hline $\begin{array}{l}\text { Knowing the target INR value } \\
\text { Yes } \\
\text { No }\end{array}$ & $\begin{array}{l}82 \\
75\end{array}$ & $\begin{array}{l}59 \\
16\end{array}$ & $\begin{array}{l}23 \\
59\end{array}$ & 0.017 & -2.003 \\
\hline $\begin{array}{l}\text { Knowing the complications } \\
\text { Yes } \\
\text { No }\end{array}$ & $\begin{array}{l}69 \\
108\end{array}$ & $\begin{array}{l}54 \\
21\end{array}$ & $\begin{array}{l}15 \\
87\end{array}$ & 0.016 & 5.417 \\
\hline
\end{tabular}

In the study, it was determined that most of the patients had laboratory tests related to OACs regularly. In the study of Gras-Champel et al. [23], it was determined that the patients comply with regular INR controls despite the low level of knowledge. In the study carried out by In the study conducted by Demirel et al. (2018), they found that almost all of the individuals (98.3\%) followed the INR value, and the majority (74.2\%) knew what values the INR value should be between. Again, in this study, the duration of drug use was between 34-55 years, and While the highest rate was 6-12 months in the 65-year-old group (43.3\%, 31.8\%), it was determined that it was 37 months-60 months in the 55-64 age group (28.6\%) [16]. In the study conducted by Mercan and Enç (2011), when patients were asked whether they carry an identity/document related to warfarin use; It is stated that $78.1 \%$ do not carry [13]. In addition, it was emphasized in this study that individuals have insufficient information about the side effects of warfarin, and therefore, do not report to the physician or nurse by ignoring emergencies. The interaction of oral anticoagulant drugs with nutrients is an issue that individuals should carefully consider [3]. Eating high-vitamin foods (broccoli, cabbage, mayonnaise, etc.) taken by nutrition may affect the metabolism of OAK [3, 24]. Nutrition with a diet rich in vitamin $\mathrm{K}$ causes a low anticoagulant effect. The intake of phylloquinone, known as vitamin $\mathrm{K} 1$, in the diet of $1-10 \mathrm{mg} /$ day changes the effect of oral anticoagulants and causes fluctuations in INR value. Studies have indicated that they do not know the food interaction with warfarin at high rates $[3,13,16]$. A study found that very few of the patients who received training on warfarin use were informed by nurses [3]. Individuals who use warfarin also need to pay attention while performing their daily activities. They should use shaving machines 
instead of razors, avoid activities that can cause injury, and contact the health institution when they see bruises in large cuts or on the body. Individuals need to know about these issues to prevent serious complications [25]. Although it is determined that the literature supports the results obtained in this research, it is thought that determining the training deficiencies related to warfarin use of patients is of great importance. Nurses who have a key role in this training should be more active.

\section{Conclusions}

This study showed that most individuals received training from the physician on warfarin treatment and followed the INR value. Most of them knew the INR value range, but most were in the uncontrolled patient group according to the effective INR value. The analysis determined the level of participant education, the reason for using warfarin, knowledge of Warfarin dosage, general knowledge about warfarin, and knowledge of Warfarin complications. According to the level of education, it was determined that the difference was due to primary school graduates who could not reach the target INR level. The difference was caused by those who knew the reason for using warfarin, and that the rate of those who knew the reason was higher than the target INR value. It was determined that those who knew the warfarin dose, who received information about warfarin, and who knew the complications had a high rate of achieving the target INR, which was the reason for the significant difference.

As a result, OAC medicines warfarin is a group of drugs beyond interacting with many drugs and foods that affect the functions of vital organs due to side effects and can cause irreversible problems in incomplete or incorrect administration cases. Therefore, the use of the drug requires care. Education programs and guidebooks specific to the needs and characteristics of each patient and their families are vital for the safe use of warfarin. In addition, it may be recommended for nurses to play a key role in increasing patient education for this drug and establishing special units for this purpose.

\section{Funding}

This research received no external funding.

\section{Acknowledgments}

This research has no acknowledgment.

\section{Conflicts of Interest}

The authors declare no conflict of interest.

\section{References}

1. Özcanl1, D. Antithrombotic Treatment and Nursing Functions. Journal of Intensive Care Nursing 2006, 10, 36-42.

2. Opie, H.L.; Gersh, B.J. Drugs For The Heart. In: Antithrombotic Agents: Platelet Inhibitors, Anticogulants and Fibrinolytics. Fox, K.A.; White, H.; Opie, J.S.; Gersh, B.; Opie, L. 7th ed. Philadelphia: Elseiver Saunders. 2009; pp. 319-24.

3. Koksal, A.T.; Avsar, G. What patients taking oral anticoagulants know and do about anticoagulant therapy: evaluation of patients in a cardiology service. Balikesir Saglik Bil Derg 2015, 4, 137-142, https://doi.org/10.5505/bsbd.2015.61587.

4. Ommaty, R. Vademecum-Cardiology. Istanbul: Medical Tribune Publishing. 2009; pp. 302-420. 
5. Anticoagulation

Europe,

Anticoagulation

Therapy.

2011, http://www.anticoagulationeurope.org/conditions/anticoagulation-therapy. Date of access 05.07.2019.

6. Yıldırım, J.G.; Temel, B.A. The validity and reliability of Turkish version of the Duke anticoagulation satisfaction scale. Turkish Journal of Chest and Cardiovascular Surgery 2014, 22, 761-72.

7. Diana, M.P.; Consuelo, R.A.; Paz, M.; Pia, L.J. Analysis of general and oral quality of life and satisfaction with treatment among anticoagulated patients. Scientonline 2015,4, 11-17.

8. Akyol, A. Antithrombotic usage indications in atrial fibrillation. Trakya Universitesi Tip Fakultesi Dergisi 2010, 27, 1-6.

9. Salman, E.; Erdoğan, K.; Sağlam, M.F.; HidiroĞLu, M. Anticoagulant Usage for Mechanic Cardiac Valve Replaced Patients and Warfarin Resistance. Ankara Medical Journal 2015, 15, 77-81.

10. Yaylacı, S.; Ösken, A.; Aydın, E.; Genç, A.B.; Şahinkuş, S.; Can, Y.; Demir, M.V.; Kocayiğit, İ.; Varım, C. Patients taking warfarin who had visited an internal medicine clinic and success rate in achieving target INR. Kocaeli Medical Journal 2014, 3, 18-21.

11. Keeling, D.; Baglin, T.; Tait, C.; Watson, H.; Perry, D.; Baglin, C.; Kitchen, S.; Makris, M.; British Committee for Standards in, H. Guidelines on oral anticoagulation with warfarin - fourth edition. British Journal of Haematology 2011, 154, 311-324, https://doi.org/10.1111/j.1365-2141.2011.08753.x.

12. Altunbas, G.; Ercan, S., Davutoglu, V.; Al, B. Overview of Warfarin Treatment and Answers to Questions. Journal of Academic Emergency Medicine 2013, 12.

13. Mercan, S.; Enç, N. Educational Needs of Patients with Warfarin. Turk J Card Nur. 2011, 2, 12-17, https://doi.org/10.5543/khd.2011.003.

14. Çırak, Y.; Savcı, S.; Karahan, Z.; Demirkılıç, U. Quality of life following acute deep vein thrombosis: the cultural adaptation, reliability and validity of the VEINES-QOL/Sym scale: a Turkish version study. Turkish Chest Cardiovascular Surgery Journal 2013, 21, 659-668, https://doi.org/10.5606/tgkdc.dergisi.2013.7463.

15. Özcan, T.; Altıok, M.; Babalıkl, F.; The effect of group education about drug usage in the patient's on warfarin therapy. Anatolian Journal of Cardiology 2013, 13, 286-94.

16. Demirel, E.; Uzun, Ş. Determining the Factors Affecting the Effective INR (International Normalization Ratio) Value in Individuals Using Warfarin. Turkish Journal of Cardiovascular Nursing 2018, 9, 58-68, https://doi.org/10.5543/khd.2018.86580.

17. Wardrop, D.; Keeling, D. The story of the discovery of heparin and warfarin. British Journal of Haematology 2008, 141, 757-763, https://doi.org/10.1111/j.1365-2141.2008.07119.x.

18. Kagansky, N.; Knobler, H.; Rimon, E.; Ozer, Z.; Levy, S. Safety of Anticoagulation Therapy in Wellinformed Older Patients. Archives of Internal Medicine 2004, 164, 2044-2050, https://doi.org/10.1001/archinte.164.18.2044.

19. Dökmeci, İ. Pharmacology-Drugs and Effects Istanbul. Alfa Publications; 2017; pp. 369-375.

20. Gray, H.H.; Dawkins, K.D.; Morgan, J.M.; Simpson, I.A. Cardiology. Translation: Hurşit Soyer. İstanbul: Nobel Medical Bookstores, 2005; pp. 90.

21. Ouirke, W.; Cahill, M.; Perera, K.; Sargent, J.; Conway, J. Warfarin prevalence, indications for use and haemorrhagic events. Irish medical journal 2007, 100, 402-404.

22. Aşiret, G.D.; Özdemir, L. Nurses' responsibilities in the safe use of anticoagulant drugs. Hacettepe University Faculty of Health Sciences Nursing Journal 2012, 19, 58-68.

23. Gras-Champel, V.; Voyer, A.; Guillaume, N.; Lematte, C.; Roussel, B.; Machu-Prestaux, C.; Andréjak, M.; Lefrère, J.-J. Quality Evaluation of the Management of Oral Anticoagulation Therapy (OAT): The Awareness of Treating Physicians and the Education of Patients Needs to Be Improved. American Journal of Therapeutics 2006, 13, https://doi.org/10.1097/01.mjt.0000158339.08483.10.

24. Göz, M.; Warfarin-food interaction: a case report and review of the literature. Turkish J Thorac Cardiovasc Surg 2006, 14, 320-324.

25. Demir, M.;Tekgündüz, E. Antithrombotic and Anticoagulant Usage Policies. Balkan Medical Journal 2010, 1, 69-73. 